\title{
Cell death in cells overlying lateral root primordia contributes to organ growth in Arabidopsis
}

\author{
Sacha Escamez ${ }^{1}$, Benjamin Bollhöner ${ }^{1}$, Hardy Hall ${ }^{1}$, Domenique Andrée ${ }^{1, a}$, Béatrice Berthet ${ }^{2}$, Ute \\ Voß $^{3}$, Amnon Lers ${ }^{4}$, Alexis Maizel ${ }^{2}$, Malcolm Bennett ${ }^{3}$ and Hannele Tuominen ${ }^{1, *}$ \\ Author information: \\ ${ }^{1}$ Umeå Plant Science Centre, Department of plant Physiology, Umeå University, 90187 Umeå, Sweden. \\ ${ }^{2}$ Center for Organismal Studies (COS), University of Heidelberg, Im Neuenheimer Feld 230, 69120 Heidelberg \\ ${ }^{3}$ Centre for Plant Integrative Biology, University of Nottingham, Nottingham LE12 SRD, United Kingdom. \\ ${ }^{4}$ Department of Postharvest Science of Fresh Produce, Agricultural Research Organization, Volcani Center, \\ Rishon LeZion, 7528809, Israel. \\ *Author for correspondence. \\ ${ }^{a}$ Current address: Umeå Plant Science Centre, Department of Forest Genetics and Plant Physiology, Swedish \\ University of Agricultural Sciences, S-901 83 Umeå, Sweden.
}

\begin{abstract}
Unlike animal development, plant organ growth is widely accepted to be determined by cell division without any contribution of cell elimination. We investigated this paradigm during Arabidopsis lateral root formation when growth of the new primordia (LRP) from pericycle-derived stem cells deep inside the root is reportedly facilitated by remodeling of the walls of overlying cells without apparent cell death. However, we observed the induction of marker genes for cell types undergoing developmental cell death in several cells overlying the growing LRP. Transmission electron microscopy, time-lapse confocal and light sheet microscopy techniques were used to establish that cell death occurred at least in a subset of endodermal LRP-overlying cells during organ emergence. Significantly, organ emergence was retarded in mutants lacking a positive cell death regulator, and restored by inducing cell death in cells overlying LRP. Hence, we conclude that in the case of LRP, cell elimination contributes to organ growth.
\end{abstract}


In contrast with the regulation of animal organ growth ${ }^{1}$, cell elimination is generally considered not to play a role in regulating plant organ growth ${ }^{2-4}$. Nevertheless, the growth of the embryo in the seed of the model plant Arabidopsis thaliana (hereafter Arabidopsis) is associated with the elimination of the neighboring endosperm tissue ${ }^{5}$. In addition, the growth of the root organ in Arabidopsis depends on cell elimination in the lateral root cap which surrounds the root tip ${ }^{6}$. Several types of cells die and degrade their own protoplast by autolysis as part of plant development, a phenomenon referred to as programmed cell death $(P C D)^{7-10}$ which implies a mechanism of cell suicide ${ }^{11-13}$. However, in cases such as the Arabidopsis endosperm the PCD framework does not apply because the death of these cells is caused by the growing embryo ${ }^{5}$. Similarly, loss of viability in cells next to growing plant organs may not only be due to endogenous (i.e. PCD) but also exogenous mechanisms. It is therefore better to describe the loss of viability and the subsequent autolysis in connection to the plant organ growth simply as "cell death" to avoid implicit mechanistic assumptions. It remains to be investigated whether such cell death events contribute, in addition to cell proliferation, to growth of neighboring organs more widely in plants.

Features of cell death and autolysis have been observed in several species in cells overlying the sites of lateral root (LR) formation within existing roots ${ }^{14-17}$. The lateral roots are initiated from a subset of pericycle cells which form the lateral root primordium (LRP) deep in the parent organ ${ }^{18,19}$. The developing LRP must therefore traverse the overlying endodermal, cortical, and epidermal cell layers for lateral root emergence (LRE) to occur. LRE has been shown to rely on cell divisions and turgordriven expansion in the $\operatorname{LRP}^{18,20}$, but also on changes in the cell walls and shapes of the LRP-overlying cells ${ }^{20-26}$. Cell death is not believed to happen during LRE in Arabidopsis ${ }^{27}$ and the cell death reported in the LRP-overlying cells of other species ${ }^{14-17}$ has not been studied in relation to LRP growth, leaving the question of whether cell death contributes to LRE open.

In Arabidopsis, the most dramatic changes reported during LRE occur in the LRP-overlying endodermal cells due to their position in immediate contact with the LRP and the presence of their lignified casparian strip cell wall region. In front of the growing LRP, endodermal cells modify their shape to such an extent that they occasionally split, with both halves having the ability to maintain their integrity at least for some time ${ }^{25}$. The cortical and epidermal cells are less affected, as their cell walls are loosened by hydrolytic enzymes so that they can separate to allow the emerging LRP to pass through ${ }^{21,27}$. There is currently no report of cell death during LRE in Arabidopsis, suggesting that the remodeling and separation of the LRP-overlying cells is sufficient to ensure LRE without any contribution from cell death. Yet, cysteine proteases associated with cell death and autolysis are expressed in LRP-overlying cells ${ }^{28}$, supporting the occurrence of cell death during LRE in Arabidopsis.

The present study revisits whether cell death occurs in the LRP-overlying cells during LRE in Arabidopsis, and if so, whether it contributes to LRP growth leading to LRE. We detected expression of several canonical marker genes for cell types undergoing developmental cell death ${ }^{29}$ in a subset of LRPoverlying cells. Electron microscopy revealed autolytic features indicative of cell death in some of the endodermal cells overlying early-stage LRPs. Live cell imaging by confocal and light sheet microscopy confirmed that cell death occurred in a subset of the LRP-overlying endodermal cells, concomitant with the growth of the LRP through the endodermis. Plants unable to express ORESARA1/ANAC092 (ORE1), a transcription factor known to activate the expression of several cell death related genes ${ }^{30}$, displayed a delay in LRE. When cell death was restored in the overlying cells of these plants by expressing the mammalian cell death promoting factor $m B A X^{31-33}$ LRP growth reverted to normal, indicating that cell death contributes to regulating organ growth during LRE.

\section{Results}

Cell death indicator genes are induced in cells overlying lateral root primordia. In a time-course transcriptomics dataset covering various stages of LRP growth $^{34}$ we detected upregulation of BIFUNCTIONAL NUCLEASE 1 (BFN1) which functions in cell autolysis associated with developmental cell 
bioRxiv preprint doi: https://doi.org/10.1101/268433; this version posted February 20, 2018. The copyright holder for this preprint (which was not certified by peer review) is the author/funder, who has granted bioRxiv a license to display the preprint in perpetuity. It is made available under aCC-BY-NC-ND 4.0 International license.

death $^{6}$ (Table S1). Several other genes expressed in cell types undergoing developmental cell death and autolysis ${ }^{29}$ were identified among the genes most correlated with BFN1 in the LRE transcriptome. Among them, METACASPASE 9 (MC9), RIBONUCLEASE 3 (RNS3), EXITUS 1 (EXI1) and DUF679 DOMAIN MEMBRANE PROTEIN 4 (DMP4) together with BFN1 represent five out of the nine core marker genes specifically expressed in cell types undergoing developmental cell death in Arabidopsis $^{29}$ and are thereafter referred to as "cell death indicator genes" (Table S1).

The five cell death indicator genes displayed three peaks of expression in the LRE transcriptome ${ }^{34}$, coinciding temporally with the passage of the growing LRP through each of the three overlying (endodermal, cortical and epidermal) cell layers (Fig. 1a). Using promoter::GUS reporter lines, we also detected activation of the promoters of the cell death indicator genes in LRP-overlying cells at different stages of LRP growth (Fig. 1b), defined according to Malamy and Benfey ${ }^{18}$. A more detailed time-lapse confocal microscopy analysis of a proBFN1::nucGFP reporter line ${ }^{35}$ carrying the proUB10::WAVE131:YFP plasma membrane marker ${ }^{36}$ revealed the activity of the BFN1 promoter in just a few endodermal cells overlying an early stage LRP, as well as in overlying epidermal cells (Fig. S1).

Next, we assessed the relationship between transcriptional induction of the cell death indicator genes and the LRP growth by calculating the proportion of LRP with proBNF1::nucGFP signal in the LRP adjacent cells that were either overlying the LRP (during early stages of LRP growth) or neighbouring the LRP (in late stages of growth) (Fig. 2a,b). A total of 204 (53.5\%) out of the 381 observed loci with LRP displayed proBNF1::nucGFP signal in at least one adjacent endodermal cell, while $56(14.7 \%)$ and 37 (9.7\%) showed signal in at least one cortical or epidermal cell, respectively. The proportion of LRP with proBNF1::nucGFP signal in at least one adjacent cell was even higher when calculated in relation to the specific stage of LRP development (Fig. 2a). In the endodermis, the frequency of proBNF1::nucGFP signal adjacent to an LRP reached its maximum (over $90 \%$ ) at stage IV, while the cortex displayed signal most frequently (nearly $50 \%$ ) at stage VII and the epidermis (40\%) at stage VIII (Fig. 2a). Interestingly, we detected lower frequency of proBNF1::nucGFP signal in cells adjacent to LRP whose growth was delayed (Fig. 2b). Taken together, these results indicate that cell death indicator genes are almost always induced in at least one LRP adjacent endodermal cell and also, however less frequently, in cortical and epidermal cells, in connection with LRP growth.

Cell death occurs in a subset of LRP-overlying cells. To determine the fate of the cells overlying the growing LRP, we employed several cell death detection methods. Terminal deoxynucleotidyl transferase dUTP nick end labeling (TUNEL), marking the DNA strand breaks which follow cell death, could be detected in the nuclei of cells close to the growing LRP (Fig. 3a). Hence, TUNEL revealed that a subset of LRP-overlying cells was undergoing autolytic processes associated with cell death.

The LRP-overlying endodermal cells displayed transcriptional activation of the cell death indicator genes more frequently than other cell types (Fig. 2a). Because endodermal cells undergo more dramatic shape changes than other overlying cell types during LRP development ${ }^{25}$, we studied the sub-cellular morphology of these cells in more detail by employing transmission electron microscopy (TEM) on root cross sections containing LRP at early stages (Fig. 3b). Plasmolysis and autolytic features indicative of cell death, such as loss of plasma membrane integrity and leakage of intracellular material outside of the protoplast, could be observed specifically in endodermal cells overlying early stage LRP (Fig. 3c-g). These TEM observations are therefore consistent with the occurrence of cell death and autolysis in a subset of LRP-overlying endodermal cells.

Endodermal cells were also observed by time-lapse confocal and light sheet microscopy using the endodermis-specific plasma membrane marker proCASP1::CITRINE:SYP122 ${ }^{25}$. We simultaneously relied on the proBFN1::nucGFP marker which not only revealed transcriptional activation of cell death related genes but also cell death itself, based on the abrupt disappearance of nuclear GFP signal known to shortly follow cell death ${ }^{6,35}$. Time-lapse confocal microscopy imaging of LRP provided evidence for the occurrence of cell death in endodermal cells overlying LRP in two out of five cases, as revealed by complete loss of nuclear GFP signal in these endodermal cells between two consecutive time points (Fig. 3h; Fig. S2). Light sheet microscopy (which provided a 12-fold greater time resolution) revealed complete disappearance of nuclear GFP signal between two consecutive time points in the LRP- 
overlying endodermal cells of two seedlings (Fig. 3i; Movies S1,2). One of these endodermal nuclei disintegrated just before losing its signal (Fig. 3i; Movies S1). Both the apparent nuclear disintegration and the rapidity of the nuclear signal disappearance can only be explained by cell death. The shapes of the plasma membranes of the LRP-overlying cells at the times of death indicated that the LRP had not yet entirely traversed the endodermis (Fig. 3h,i; Fig. S2; Movie S3), meaning that the observed cell death events occurred either before or during the passage of the LRP through the endodermal layer. A number of surviving endodermal cells in close proximity to LRP displayed a slow and gradual decrease of the nuclear GFP signal (Fig. 3h,i; Fig. S2), suggesting deactivation of the cell death and autolysis transcriptional machinery in these cells. A few other endodermal cells kept a high level of nuclear GFP signal over the observation time span (Fig. 3i; Fig. S2) and it cannot be concluded whether or not these cells would have died at a later point during LRP emergence.

The height of the dome shape of five LRP observed with time-lapse confocal microscopy was measured at the same time points at which the endodermal nuclear GFP fluorescence was recorded, revealing accelerations of LRP growth concomitant with the death of an overlying endodermal cell (Fig. $3 \mathrm{j}$,k; Fig. S2). Albeit weakly, LRP growth was on average better correlated with the dynamics of nuclear GFP signal intensity of the overlying endodermal cells that died (squared Pearson correlation coefficient $\left.r^{2}=0.32\right)$ than with the nuclear signal dynamics of the non-dying cells $\left(r^{2}=0.03\right)$, suggesting causality between LRP progression and endodermal cell death.

Cell death in LRP-overlying cells facilitates LRP growth. We reasoned that if cell death played a role in facilitating LRP growth, then plants impaired in parts of the cell death machinery may show delayed LRE. To compare the speed of LRE between genotypes, LR initiation was induced synchronously by gravitational stimulus $\left(90^{\circ}\right.$ rotation of the seedlings) ${ }^{18,20}$. When monitored at $18 \mathrm{~h}$ and $42 \mathrm{~h}$ postgravitational induction (pgi), the single mutants for the cell death indicator genes did not show any consistent or significant changes in LRP growth (Fig. S3), possibly because of functional redundancy.

A large number of cell death related genes, including the five cell death indicators identified in this study, are transcriptionally regulated by the NAC transcription factor ORESARA1/ANAC092 $(\mathrm{ORE1})^{30}$. ORE1 is expressed in connection with several types of developmental cell death and autolysis ${ }^{37}$ and is also connected to LR development ${ }^{38}$. We therefore hypothesized that ORE1 might contribute to the transcriptional control of cell death in the LRP-overlying cells, and that analyzing LRP growth in the ore 1 mutants could overcome potential genetic redundancies between cell death related genes during LRE. Consistent with a role for ORE1 during LRE, shorter LRs were observed in two ore 1 mutant alleles compared to wild-type seedlings (Fig. S4a-c). Gravitational induction experiments also revealed delayed LRP growth in these ore1 mutants (Fig. 4a).

To test whether ore 1 mutants displayed slower LRP growth as a result of altered cell death in the overlying cells, we set out to rescue the LRE delay of ore 1 by inducing cell death in cells overlying LRP. To do this, we expressed the pro-apoptotic mammalian protein $\mathrm{mBAX}^{31}$, known to potently induce cell death in Arabidopsis ${ }^{32,33}$, under the transcriptional control of the BFN1 promoter (proBFN1::mBAX) in the ore1-2 background. This line expressed mBAX (Fig. S4d) and showed signs of cell death in front of LRP (Fig. S5), but did not display obvious alterations in plant development most probably because the BFN1 promoter is active only at a late stage of development in cells that are anyway destined to $\mathrm{die}^{29}$.

Interestingly, the LRP growth was restored to at least wild-type level in the ore1-2 mutants expressing $m B A X$ under the transcriptional control of the BFN1 promoter (Fig. $4 \mathrm{~b}$; Fig. S4b,c,f). The fact that the cell death inducing proBFN1::mBAX construct had a rescuing effect on LRE in ore1-2 (Fig. 4b; Fig. S4f) but no effect in the wild-type plants (Fig. S4e) indicates that ORE1 regulates cell death which normally occurs in cells overlying LRPs. Collectively, the correlation between LRP growth dynamics and overlying cell death (Fig. S2), and the rescue of LRP growth in ore1-2 by introducing expression of mBAX show that cell elimination contributes to regulating LRP growth. 


\section{Discussion}

Our study demonstrates that, contrary to what was previously thought, cell death occurs in cells overlying LRP in Arabidopsis and also contributes to regulating LRP growth. The occurrence and relevance of cell elimination during LRE of Arabidopsis is likely to have been previously overlooked for several reasons. First, it is clear that living LRP-overlying cells undergo a number of major changes which contribute to $\mathrm{LRE}^{20-26}$, rendering the occurrence of cell death seemingly unnecessary. Second, cell death has not been observed during LRE in Arabidopsis probably because following cell death of a few cells among a large number of viable cells is difficult unless high-resolution methods and suitable markers are used. Monitoring of plasma membrane or tonoplast integrity by confocal microscopy of membrane markers or propidium iodide staining ${ }^{25}$ may not have provided the necessary resolution and contrast to unequivocally detect cell death of these few cells. Furthermore, the mechanism of cell death in LRP-overlying cells is not known and may differ from other instances of developmental cell elimination. This is supported by the fact that only five of the nine canonical Arabidopsis developmental cell death indicator genes ${ }^{29}$ were highly co-expressed during LRE (Table S1; Fig. 1a). In addition, expression of a tonoplast integrity marker ${ }^{6}$ under the control of the BFN1 promoter revealed a longer time gap between transcriptional activation of this promoter and loss of tonoplast integrity in LRP-overlying cells than in xylem tracheary elements (Movie S4) which undergo a well-studied case of developmental cell death and autolysis ${ }^{39}$. Moreover, a lag of several hours could be observed with the tonoplast integrity marker ${ }^{6}$ between the loss of tonoplast integrity and the disappearance of nuclear signal in LRP-overlying endodermal cells (Movie S5), unlike in other dying cell types ${ }^{6,40}$. Finally, if one carefully looks at published images of emerging lateral roots, it is possible to distinguish cells whose collapsed morphology is suggestive of their death (see for instance Figure $1 \mathrm{c}$ in ${ }^{41}$ ). Hence, our observations are not necessarily in conflict with earlier observations in Arabidopsis, and are further supported by observations of the demise of cells overlying LRP in other species ${ }^{14-17}$.

The spatial and temporal pattern of cell death progression during LRE suggests the existence of a signal responsible for activating the genetic modules of cell elimination. Both LRP growth and remodeling of LRP-overlying cells rely to a significant extent on the hormone auxin ${ }^{20,23,24}$. Auxin also accumulates in several cell types that ultimately undergo developmental cell death ${ }^{42,43}$. However, the cell death and autolysis related genes studied here are not known to be induced by auxin except for $O R E 1^{38}$. It is therefore conceivable that auxin triggers a signaling cascade towards cell death and autolysis in front of the LRP through induction of upstream regulators such as ORE1. On the other hand, ORE1 does not appear to be a primary auxin response gene as its induction by this hormone is slower than by abscisic acid (ABA) or the ethylene precursor $\mathrm{ACC}^{38}$. Hence, we propose that the induction of cell death and autolysis in the LRP-overlying cells involves primarily other signals than auxin. Credible candidates include ABA and ethylene.

Mechanical forces are also expected to influence the fate of the LRP-overlying cells. Strong mechanical pressure is likely to be exerted by the LRP growing against the overlying cells which themselves alter their mechanical properties and rigidity in coordination with LRP growth ${ }^{20,22}$. This could eventually result in the death of some weakened overlying cells under intense pressure. Such a scenario is analogous to the elimination of Arabidopsis endosperm cells which, by loosening their cell walls, allow the embryo to grow into the space that they occupy and then mechanically kill them ${ }^{5}$. Similarly, during adventitious root formation, mechanical pressure has been reported to induce cell death in the epidermis of rice in an ethylene-dependent manner ${ }^{44}$. It is therefore possible that mechanical pressure represents at least one of the mechanisms involved in cell death signaling, or even in the execution of cell death itself, during LRP growth. Furthermore, such LRP-mediated mechanical pressure would likely affect the overlying cells differently depending on their own mechanical properties and on their degree of overlap with the growing LRP, thereby providing a possible explanation for the fact that only a subset of the LRP-overlying cells dies.

We furthermore demonstrated that cell death contributes, along with several other processes ${ }^{20-26}$, to the growth of the LRP. Even though the underlying mechanism remains to be tested, it is likely that cell death facilitates growth of the LRP by reducing the mechanical resistance of the overlying cells 
towards the primordia. The plausibility of such mode of action based on mechanical feedback is supported by the fact that laser-ablation of an endodermal cell is potent enough to trigger LR initiation in the adjacent pericycle ${ }^{45}$, likely because the loss of mechanical feedback from the ablated cell allows the necessary swelling of the pericycle to initiate LRP formation ${ }^{25,46}$. Alternatively, or in addition, cell death might contribute to cell wall remodeling and cell separation and hence to LRP growth by allowing a massive release of cell wall modifying enzymes and/or of auxin. For example, cell death of a few columella stem cell daughter cells in Arabidopsis roots exposed to low temperature was recently shown to affect auxin distribution ${ }^{47}$. Furthermore, the developmental cell death of lateral root cap (LRC) cells was shown to result in release of auxin that is necessary for LR initiation ${ }^{43}$. Interestingly, LRP growth was delayed to a comparable extent in mutants for ORE1 and for the LATERAL ORGAN BOUNDARIES-DOMAIN/ASYMMETRIC LEAVES 2-LIKE29 (LBD29) transcription factor, which normally controls auxin accumulation in LRP-overlying cells ${ }^{23}$ (Fig. 4; Fig. S4a). It is therefore tempting to hypothesize that the death of LRP-overlying cells may serve an analogous purpose to LRC cell death in quickly releasing high amounts of auxin for cell wall remodeling of other overlying cells and for LRP growth.

Our finding on the impact of cell death on lateral root growth demonstrates that plant organ growth can be regulated by cell elimination. It was also recently shown that embryo growth requires cell death of the bordering endosperm ${ }^{5}$ and that root organ growth is regulated by cell death in a cell type which borders its tip ${ }^{6}$. These findings therefore call for a major shift in opinion to accept that cell proliferation is not the sole factor determining organ growth in plants and that the regulation of organ growth in plants is not as dissimilar from that in animals as previously proposed.

This greater similarity than previously accepted in the regulation of organ growth between animals and plants raises some evolutionary questions. Has cell elimination arisen as a mechanism to regulate organ growth from a shared evolutionary heritage between animals and plants, for example from the regulation of early unicellular populations by cell death ${ }^{8}$ ? Alternatively, could the regulation of organ growth by cell death in animals and plants have stricken roots at different locations in the tree of life, making it a form of convergent evolution which may reveal in the future some form of deep evolutionary constraint linked with cell elimination?

\section{Acknowledgements}

We thank Joop Vermeer for the proCASP1::CITRINE:SYP122 line, Moritz Nowack for the tonoplast integrity marker, Laszlo Bako for the proLBD16::GFP line, Michael Wilson and Kim Kenobi for bioinformatic assistance, Kamal Swarup and Julien Lavenus with confocal imaging, and Lenore Johansson from the Umeå Core Facility for Electron Microscopy (UCEM) for technical assistance. This work was supported by the Swedish Research Council VR (621-2013-4949), the Swedish Research Council Formas (232-2009-1698), and the Swedish Governmental Agency for Innovation Systems VINNOVA (015-02290) as well as by the Boehringer Ingelheim Fundation and Deutsch Forschung Gemeinschaft (FOR2581) and Landesgraduiertenförderung to BBe and AM.

\section{Author contributions}

H.T. and M.B. conceived the study. S.E., B.Bo., H.H., D.A., and B.Be. performed the experiments, A.M., M.B., S.E., B.Bo. and H.T. supervised the experiments, and S.E. and H.T. wrote the manuscript.

\section{Competing interests}

The authors declare no competing interest.

\section{Material and Methods}

\section{Plant Material and Growth conditions}

Most of the Arabidopsis plants used in this study are in the Columbia-0 (Col-0) genetic background, and were therefore compared with a Col-0 wild type: anac092-1 (ore1 allele SALK_090154 ${ }^{30}$ ), ore1-2 $\left(5 \mathrm{bp}\right.$ deletion $\left.{ }^{48}\right), b f n 1-1$ (GK-197G126), bfn1-2 (SALK_017287), mc9-1 (GABI_540_H06 35 ), mc9-2 
(SALK_07581435), SALK_063946C (for DMP4), SAIL_195_E01 (for RNS3), SAIL_760_G07 and SALK_137383C (for EXI1). The FLAG_164A04 allele for RNS3 was in the Wassilewskija (Ws) genetic background, and compared to the corresponding wild type.

To compare the speed of LRE between genotypes, seedlings were grown on $1 / 2 \mathrm{MS}$ medium for three days in constant light $\left(150 \mu \mathrm{E} \cdot \mathrm{m}^{-2} \cdot \mathrm{s}^{-1}\right)$ on vertical plates, which were then rotated $90^{\circ}$ to induce LRP initiation ${ }^{20}$. Determination of LRP stage was performed $18 \mathrm{~h}$ and $42 \mathrm{~h}$ after synchronized LR induction by gravitational stimulus on cleared samples observed as described previously ${ }^{18,20}$.

Seedlings whose naturally initiated LRPs (no induction) were observed with any of the presented microscopy techniques were grown on $1 / 2 \mathrm{MS}$ medium for $5-7$ days in $16 \mathrm{~h}$ day $\left(150 \mu \mathrm{E} \cdot \mathrm{m}^{-2} \cdot \mathrm{s}^{-1}\right) / 8 \mathrm{~h}$ night cycles.

\section{BFN1 co-expression analysis}

To identify genes correlating in expression with BFN1 during LR development, smooth splines were fitted through the transcriptomic profiles for all genes, to smooth out the noise. The Pearson correlation between each gene's profile and that of the target gene BFN1 was calculated, including all data points, i.e. not just mean values for each time point. Genes were ranked in decreasing order of the Pearson correlation with BFN1.

\section{Cloning and plant transformation}

For promoter-reporter constructs, 1654 bp (AT4G18425; DMP4) or 2000 bp (AT1G26820; RNS3) upstream of the translational start codon were amplified and recombined by Gateway-mediated cloning via pENTR207 (Invitrogen) into the destination vectors pBGGUS ${ }^{49}$. Col-0 plants were transformed with Agrobacterium tumefaciens by floral dip as previously described ${ }^{50}$. At least five independent lines were analysed for each construct to select representative lines. proBFN1::GUS was obtained by recombining a 670 bp promoter region of BFN1 into pMDC163. proBFN1::nucGFP, proMC9::nucGFP and proMC9::MC9:GUS have been described previously ${ }^{35}$.

To place the tonoplast integrity (ToIM) marker ${ }^{6}$ downstream of the BFN1 promoter, the promoter of the putative protease PASPA3 previously cloned upstream of the tonoplast integrity marker ${ }^{6}$ was replaced by the BFN1 promoter. To do so, the BFN1 promoter was amplified from a plasmid using primers comprising the attB4 and attB1r sequences, and recombined into pDONR P4P1r. The PASPA3 promoter from pK7m34GW-pPASPA3-eGFP-2A-sp-mRFP $P^{6}$ was removed by a standard BP recombination with pDONRP4P1r, the destination vector was recovered by selecting on Chloramphenicol and Spectinomycin in DB3.1 cells and subsequently recombined during an LR reaction with pENTRL4R1-pBFN1. The resulting expression vector pK7m34GW-pBFN1-eGFP-2A-sp-mRFP was used to electroporate Agrobacterium tumefaciens. Agrobacterium-mediated floral dip transformation of wild-type (Col-0) plants was performed and several apparent transformants were screened for visible ToIM signal, leading to the selection of a representative proBFN1::TolM marker line.

To express the cell death agonist mammalian protein $\mathrm{mBAX}$ under the transcriptional control of the BFN1 promoter, the vectors pENTRL4R1 containing the proBFN1 fragment and pENTR221 containing the $m B A X$ gene (kind gift from Moritz Nowack; unpublished) were together recombined into pK7m24GW51 using standard protocols for LR recombination. This vector was transferred into Agrobacterium tumefaciens which were used to transform by floral dip Col-0 and ore1-2 plants. Transformants were then screened to identify at least one homozygous line in each genotype displaying $m B A X$ expression.

\section{Confocal Laser Scanning Microscope (cLSM) analyses}

3D-projections of LRP from Figure S1 were recorded as previously described ${ }^{22,52}$ with a Leica SP5 CLSM in intervals of $1 \mathrm{~h}$, using 488nm and 514nm laser lines sequentially to excite GFP and YFP, respectively.

All other CLSM images were acquired using a Zeiss LSM780 inverted microscope, by placing the seedlings in microscope chambers as previously described ${ }^{53}$. GFP and CITRINE signals (Figure 2; Figure S2) were simultaneously recorded with a spectral detector after excitation with a 488nm laser line, and separated by online fingerprinting (i.e. unmixing which occurs during, rather than after, 
acquisition). eGFP and mRFP signals (Movies S1, S2) from the TolM marker ${ }^{6}$ were detected simultaneously upon excitation with 488nm (for eGFP) and 561nm (for mRFP) laser lines.

\section{Transmission electron microscopy}

An early-stage LRP marker proLBD16::GFP line (a kind gift from Laszlo Bako) was used to identify regions of the root containing primordia. Tissues were fixed under vacuum in $2.5 \% \mathrm{w} / \mathrm{v}$ glutaraldehyde in $0.1 \mathrm{M} \mathrm{Na}$ cacodylate buffer, pH7.3 for $30 \mathrm{~min}$, and then without vacuum overnight at $4^{\circ} \mathrm{C}$. Tissues were then stained with $1 \% \mathrm{w} / \mathrm{v}$ osmium tetroxide for $2 \mathrm{~h}$ at room temperature in the dark, washed twice in water, and then dehydrated in 15-minute steps through an ethanol series $(50,70,90$, and $100 \%)$. Root portions were then rinsed in propylene oxide and exchanged with Spurr's resin (Polysciences) and then baked at $65^{\circ} \mathrm{C}$ for 2 days. Sections were mounted on formvar-coated copper grids. Contrasting was done for $45 \mathrm{~min}$ in $5 \%$ uranyl acetate followed by $5 \mathrm{~min}$ in Sato's lead acetate staining.

\section{Light microscopy}

All observations were performed with a Zeiss Axioplan II microscope equipped for epifluorescence microscopy.

Histochemical GUS assays were performed as described previously ${ }^{35}$. Seedlings were cleared and observed using differential interference contrast ${ }^{18}$.

LRP of seedlings harbouring the proBFN1::nucGFP constructs were observed while alive following mounting in liquid $1 / 2$ MS medium. Both differential interference contrast and fluorescence micrographs were acquired to relate the possible presence of nucGFP signal to the LRP stage.

For TUNEL staining, seedlings were fixed for $2 \mathrm{~h}$ in freshly prepared $4 \%$ paraformaldehyde in phosphate buffered saline (PBS) $\left(137 \mathrm{mM} \mathrm{NaCl}, 2.7 \mathrm{mM} \mathrm{KCl}, 8 \mathrm{mM} \mathrm{Na}_{2} \mathrm{HPO}_{4}, 2 \mathrm{mM} \mathrm{KH}_{2} \mathrm{PO}_{4}\right)$, and washed twice with PBS. Samples were permeabilized by 8 min incubation at room temperature in a solution containing $0.1 \%$ Triton X-100 and $0.1 \%$ trisodium citrate, followed twice by PBS wash. TUNEL labeling was performed according to manufacturer's protocol (In Situ Cell Death Detection Kit, TMR red, Roche), and washed twice with PBS. Nuclei were stained by incubating samples for $10 \mathrm{~min}$ in the dark in $100 \mu \mathrm{l}$ of 4',6-diamidino-2-phenylindole (DAPI) solution (1 $\mu \mathrm{g} / \mathrm{ml}$ in PBS), followed by three washing steps with PBS, each for 20 min.

\section{Lightsheet fluorescence microscopy}

Seeds were sterilized for $10 \mathrm{~min}$ with $70 \%$ ethanol supplemented with $0.05 \%$ Triton $\mathrm{X} 100$, washed 3 times with $70 \%$ ethanol, and incubated for 10 min with $100 \%$ ethanol before being dried out under the sterile bench. Glass capillaries ( $1.8 \mathrm{~mm}$ of diameter, Blaubrand intraMark, glass micropipettes $100 \mu \mathrm{L}$ Ref. 708744 ) were sterilized with $70 \%$ ethanol for $20 \mathrm{~min}$, then $100 \%$ ethanol for $20 \mathrm{~min}$ and left to dry. The capillaries were filled with $1 / 2 \mathrm{MS}$ medium buffered with $0.5 \mathrm{~g} / \mathrm{L}$ MES (adjusted to $\mathrm{pH} 5,8$ with $\mathrm{KOH})$, containing $1 \%(\mathrm{~m} / \mathrm{V})$ of Phytagel (Sigma Phytage $\left.\mathrm{I}^{\mathrm{TM}} \mathrm{P} 8169-250 \mathrm{G}\right)$ and placed in a small round plate filled with the same medium. One seed was placed on top of each capillary and stratified for $48 \mathrm{~h}$ before transfer to long day conditions for 4 to 5 days at $22^{\circ} \mathrm{C}$.

Imaging was performed on a Luxendo MuViSPIM, equipped with two-sided illumination and two cameras for detection. In the microscope, the plant was continuously illuminated (red and blue LEDs, turned off during stack acquisition) and temperature was maintained at $24^{\circ} \mathrm{C}$. About $5 \mathrm{~mm}$ of the root surrounded by a cylinder of Phytagel medium was extruded out of the glass capillary which itself was positioned vertically in the microscope's chamber containing liquid, sterile $1 / 2 \mathrm{MS}$ medium. The shoots of the seedling were left out of the liquid medium.

Samples were excited by a $488 \mathrm{~nm}$ laser light sheet $(2.5 \mu \mathrm{m}$ thickness at the waist) generated with Nikon Plan Fluor 10X/0.30W objectives. Laser power was kept $<6 \mathrm{~mW}$. The emitted fluorescence was detected by Nikon Apo 40X/0.80W DIC N2 objectives associated with a 497-553 nm band pass filter and captured using 2 Hamamatsu Orca-flash 4.0 cameras with an exposure time $<100 \mathrm{~ms}$. Under these conditions, both reporters (cell death marker proBFN1::nucGFP and plasma membrane marker proCASP1::CITRINE:SYP122) were collected in the same channel. Stacks were acquired every $10 \mathrm{~min}$ 
for $24 \mathrm{~h}$ with a $\mathrm{z}$-step of $0.250 \mu \mathrm{m}$ spanning a total volume of $200 \mu \mathrm{m}$ containing the growing LRP and the primary root overlying tissues.

After fusion of the two opposite views with the proprietary script of Luxendo, sample drift was corrected using the BigDataTracker plugin in ImageJ (Fiji).

\section{References}

1. Gokhale, R.H. \& Shingleton, A.W. Size control: the developmental physiology of body and organ size regulation. Wiley Interdisciplinary Reviews: Developmental Biology 4, 335-356 (2015).

2. Mizukami, Y. \& Fischer, R.L. Plant organ size control: AINTEGUMENTA regulates growth and cell numbers during organogenesis. Proceedings of the National Academy of Sciences 97, 942947 (2000).

3. Meyerowitz, E.M. Genetic control of cell division patterns in developing plants. Cell 88, 299308 (1997).

4. Harashima, H. \& Schnittger, A. The integration of cell division, growth and differentiation. Curr Opin Plant Biol 13, 66-74 (2010).

5. Fourquin, C. et al. Mechanical stress mediated by both endosperm softening and embryo growth underlies endosperm elimination in Arabidopsis seeds. Development, dev. 137224 (2016).

6. Fendrych, M. et al. Programmed cell death controlled by ANAC033/SOMBRERO determines root cap organ size in Arabidopsis. Curr Biol 24, 931-940 (2014).

7. Lockshin, R.A. \& Williams, C.M. Programmed cell death-II. Endocrine potentiation of the breakdown of the intersegmental muscles of silkmoths. Journal of Insect Physiology 10, 643649 (1964).

8. Ameisen, J.C. On the origin, evolution, and nature of programmed cell death: a timeline of four billion years. Cell Death \& Differentiation 9, 367-393 (2002).

9. Daneva, A., Gao, Z., Van Durme, M. \& Nowack, M.K. Functions and regulation of programmed cell death in plant development. Annu Rev Cell Dev Bi 32, 1-28 (2016).

10. Galluzzi, L. et al. Essential versus accessory aspects of cell death: recommendations of the NCCD 2015. Cell Death \& Differentiation 22, 58-73 (2015).

11. Noble, D. Evolution beyond neo-Darwinism: a new conceptual framework. Journal of Experimental Biology 218, 7-13 (2015).

12. Planer, R.J. Replacement of the "genetic program" program. Biology \& Philosophy 29, 33-53 (2014).

13. Reynolds, A.S. The deaths of a cell: how language and metaphor influence the science of cell death. Studies in History and Philosophy of Science Part C: Studies in History and Philosophy of Biological and Biomedical Sciences 48, 175-184 (2014).

14. Bell, J. \& McCully, M.E. A histological study of lateral root initiation and development inZea mays. Protoplasma 70, 179-205 (1970).

15. Bonnett Jr, H.T. Cortical cell death during lateral root formation. The Journal of cell biology 40, 144 (1969).

16. Karas, I. \& McCully, M.E. Further studies of the histology of lateral root development inZea mays. Protoplasma 77, 243-269 (1973).

17. Kosslak, R.M., Chamberlin, M.A., Palmer, R.G. \& Bowen, B.A. Programmed cell death in the root cortex of soybean root necrosis mutants. The Plant Journal 11, 729-745 (1997).

18. Malamy, J.E. \& Benfey, P.N. Organization and cell differentiation in lateral roots of Arabidopsis thaliana. Development 124, 33-44 (1997).

19. Stocking, C. Histology and development of the root, in Pflanze und Wasser/Water Relations of Plants 173-187 (Springer, 1956).

20. Péret, B. et al. Auxin regulates aquaporin function to facilitate lateral root emergence. Nature cell biology 14, 991-998 (2012). 
21. Kumpf, R.P. et al. Floral organ abscission peptide IDA and its HAE/HSL2 receptors control cell separation during lateral root emergence. Proceedings of the National Academy of Sciences 110, 5235-5240 (2013).

22. Lucas, M. et al. Lateral root morphogenesis is dependent on the mechanical properties of the overlaying tissues. Proceedings of the National Academy of Sciences 110, 5229-5234 (2013).

23. Porco, S. et al. Lateral root emergence in Arabidopsis is dependent on transcription factor LBD29 regulating auxin influx carrier LAX3. Development 143, 3340-3349 (2016).

24. Swarup, K. et al. The auxin influx carrier LAX3 promotes lateral root emergence. Nature cell biology 10, 946-954 (2008).

25. Vermeer, J.E. et al. A spatial accommodation by neighboring cells is required for organ initiation in Arabidopsis. Science 343, 178-183 (2014).

26. Vissenberg, K., Martinez-Vilchez, I.M., Verbelen, J.-P., Miller, J.G. \& Fry, S.C. In vivo colocalization of xyloglucan endotransglycosylase activity and its donor substrate in the elongation zone of Arabidopsis roots. The Plant Cell 12, 1229-1237 (2000).

27. Vilches-Barro, A. \& Maizel, A. Talking through walls: mechanisms of lateral root emergence in Arabidopsis thaliana. Curr Opin Plant Biol 23, 31-38 (2015).

28. Hierl, G., Vothknecht, U. \& Gietl, C. Programmed cell death in Ricinus and Arabidopsis: the function of KDEL cysteine peptidases in development. Physiologia plantarum 145, 103-113 (2012).

29. Olvera-Carrillo, Y. et al. A conserved core of programmed cell death indicator genes discriminates developmentally and environmentally induced programmed cell death in plants. Plant Physiol 169, 2684-2699 (2015).

30. Balazadeh, S. et al. A gene regulatory network controlled by the NAC transcription factor ANAC092/AtNAC2/ORE1 during salt-promoted senescence. The Plant Journal 62, 250-264 (2010).

31. Czabotar, P.E., Lessene, G., Strasser, A. \& Adams, J.M. Control of apoptosis by the BCL-2 protein family: implications for physiology and therapy. Nature reviews Molecular cell biology 15, 4963 (2014).

32. Dou, D. et al. Conserved C-terminal motifs required for avirulence and suppression of cell death by Phytophthora sojae effector Avr1b. The Plant Cell 20, 1118-1133 (2008).

33. Evangelisti, E. et al. The Phytophthora parasitica RXLR effector penetration-specific effector 1 favours Arabidopsis thaliana infection by interfering with auxin physiology. New Phytologist 199, 476-489 (2013).

34. Voß, U. et al. The circadian clock rephases during lateral root organ initiation in Arabidopsis thaliana. Nature communications 6 (2015).

35. Bollhöner, B. et al. Post mortem function of AtMC9 in xylem vessel elements. New Phytologist 200, 498-510 (2013).

36. Geldner, N. et al. Rapid, combinatorial analysis of membrane compartments in intact plants with a multicolor marker set. The Plant Journal 59, 169-178 (2009).

37. Matallana-Ramirez, L.P. et al. NAC transcription factor ORE1 and senescence-induced BIFUNCTIONAL NUCLEASE1 (BFN1) constitute a regulatory cascade in Arabidopsis. Molecular plant 6, 1438-1452 (2013).

38. He, X.J. et al. AtNAC2, a transcription factor downstream of ethylene and auxin signaling pathways, is involved in salt stress response and lateral root development. The Plant Journal 44, 903-916 (2005).

39. Escamez, S. \& Tuominen, H. Programmes of cell death and autolysis in tracheary elements: when a suicidal cell arranges its own corpse removal. Journal of Experimental Botany 65, 13131321 (2014).

40. Pesquet, E., Korolev, A.V., Calder, G. \& Lloyd, C.W. The Microtubule-Associated Protein AtMAP70-5 regulates secondary wall patterning in Arabidopsis wood cells. Curr Biol 20, 744749 (2010). 
41. Péret, B., Larrieu, A. \& Bennett, M.J. Lateral root emergence: a difficult birth. Journal of Experimental Botany 60, 3637-3643 (2009).

42. De Rybel, B. et al. Integration of growth and patterning during vascular tissue formation in Arabidopsis. Science 345, 1255215 (2014).

43. Xuan, W. et al. Cyclic programmed cell death stimulates hormone signaling and root development in Arabidopsis. Science 351, 384-387 (2016).

44. Steffens, B., Kovalev, A., Gorb, S.N. \& Sauter, M. Emerging roots alter epidermal cell fate through mechanical and reactive oxygen species signaling. The Plant Cell 24, 3296-3306 (2012).

45. Marhavý, P. et al. Targeted cell elimination reveals an auxin-guided biphasic mode of lateral root initiation. Genes \& Development 30, 471-483 (2016).

46. Vermeer, J.E. \& Geldner, N. Lateral root initiation in Arabidopsis thaliana: a force awakens. F1000prime reports 7 (2015).

47. Hong, J.H. et al. A Sacrifice-for-Survival Mechanism Protects Root Stem Cell Niche from Chilling Stress. Cell 170, 102-113. e114 (2017).

48. Kim, J.H. et al. Trifurcate feed-forward regulation of age-dependent cell death involving miR164 in Arabidopsis. Science 323, 1053-1057 (2009).

49. Kubo, M. et al. Transcription switches for protoxylem and metaxylem vessel formation. Genes \& Development 19, 1855-1860 (2005).

50. Clough, S.J. \& Bent, A.F. Floral dip: a simplified method forAgrobacterium-mediated transformation ofArabidopsis thaliana. The Plant Journal 16, 735-743 (1998).

51. Karimi, M., Inzé, D. \& Depicker, A. GATEWAY'M vectors for Agrobacterium-mediated plant transformation. Trends Plant Sci 7, 193-195 (2002).

52. Lucas, M. et al. Short-Root regulates primary, lateral, and adventitious root development in Arabidopsis. Plant Physiol 155, 384-398 (2011).

53. Marhavý, P. \& Benková, E. Real-time analysis of lateral root organogenesis in Arabidopsis. Bioprotocol 5 (2015). 
bioRxiv preprint doi: https://doi org/10.1101/268433: this version posted February 20, 2018. The copyright holder for this preprint (which was not certified by peer review) is the author/funder, who has granted bioRxiv a license to display the preprint in perpetuity. It is made available under aCC-BY-NC-ND 4.0 International license.

Figure 1: Transcriptional activation of cell death indicator genes in LRP-overlying cells

(a) Expression profile of BFN1 and four highly correlated cell death indicator genes in the lateral root (LR) emergence time course transcriptomics dataset from ref 34.

(b) Promoter activity profile of the cell death indicator genes BFN1, MC9, DMP4 and RNS3 in the tissues overlying naturally initiated lateral root primordia (LRP) at the indicated stages. Bars $=25 \mu \mathrm{m}$. Note that in addition to signal in the overlying cells there is also often signal in the protoxylem vessel.

Figure 2: Transcriptional activation of cell death indicator genes in LRP-overlying cells

(a) Proportion of LR primordium (LRP) displaying nuclear GFP signal in at least one LRP adjacent endodermal cell (red), cortical cell (orange), or epidermal cell (purple) for each stage of LRP development in the proBFN1::nucGFP seedling roots. Values represent averages of three replicate experiments, each including 20 seedlings and over 100 primordia. Error bars indicate SD. The micrographs in the lower panels illustrate how the data was acquired by differential interference contrast microscopy (upper row) for analysis of the LRP stage and by fluorescence microscopy (lower row) for GFP signal count in the marker line proBFN1::nucGFP. The LRP shape is delineated by a white line in the fluorescence micrographs. Bars $=25 \mu \mathrm{m}$.

(b) Visualization of LRP stage distribution in terms of LRP sequence from the root tip of 60 5-6 days old Arabidopsis seedlings. The size of each dot is proportional to the number of observed LRP at each stage and position in total (grey) or with at least one proBFN1::nucGFP-positive overlying cell (green). $\mathrm{E}=$ emerged.

\section{Figure 3: Detection of cell death in LRP-overlying cells}

(a) Fluorescence micrography detection of cell death-associated nuclear degradation with TUNEL (red) and ubiquitous nuclear staining with DAPI (blue). Arrowheads indicate TUNEL-positive nuclei in LRPoverlying cells. Bar $=50 \mu \mathrm{m}$.

(b-g) Transmission electron micrography of cross sections through a lateral root primordium (LRP) and the surrounding tissues. The position of the cross section within the root is shown in (b). Stage II (c,d) and stage III (e-g) LRPs are shown. (d) is a magnification from (c). (g) is a magnification of (f) which itself is a magnification of (e). The arrowhead indicates apparent loss of plasma membrane integrity while the asterisk indicates leakage of intracellular material. LRP, lateral root primordium; CC, cortical cell. Bar $=5 \mu \mathrm{m}$ (c,e), $2 \mu \mathrm{m}$ (f) and $0.5 \mu \mathrm{m}$ (d).

(h) Time-lapse confocal microscopy 3D projection of the endodermal plasma membrane marker proCASP1::CIT:SYP122 (purple) and the nuclear cell death reporter proBFN1::nucGFP (green) around a developing LRP. The asterisks mark the endodermal cell which ultimately dies (between $10 \mathrm{~h}$ and $12 \mathrm{~h}$ ) while the arrowheads point at the endodermal nuclei displaying GFP signal. The elongated area with GFP signal seen in the stele from $2 \mathrm{~h}$ to $6 \mathrm{~h}$ is the nucleus of a xylem tracheary element undergoing developmental cell death and autolysis. Bar $=25 \mu \mathrm{m}$.

(i) Kymographs of 3D projection from light sheet microscopy time-lapse imaging of the endodermal plasma membrane marker proCASP1::CIT:SYP122 and the nuclear-localized cell death indicator gene transcriptional reporter proBFN1::nucGFP around a developing LRP. The presence of a LRP can be deduced from the bent shape of the overlying endodermal cells. Asterisks indicate time points when an endodermal nucleus is seen to disintegrate or to disappear. Arrowheads point at disintegrating nuclei. Bars $=20 \mu \mathrm{m}$.

(j) Transmission light images corresponding to images in (h). The LRP are highlighted by white lines. Bars $=25 \mu \mathrm{m}$.

(k) Dome height (in $\mu \mathrm{m}$ ) of the LRP from $(\mathrm{h}, \mathrm{j})$ over the $12 \mathrm{~h}$ monitoring period of LRE. The black arrow indicates acceleration of LRP growth along its length axis concomitant with the death of an overlying cell.

Figure 4: LRE is delayed by loss of the positive cell death regulator ORE1 and rescued by inducing cell death in overlying cells 
(a) Distribution of observed lateral root primordium (LRP) stages $18 \mathrm{~h}$ and $42 \mathrm{~h}$ after gravitational induction of lateral root (LR) initiation in wild type (WT) and two mutant alleles for ORE1.

(b) Distribution of observed LRP stages $18 \mathrm{~h}$ and $42 \mathrm{~h}$ after gravitational induction of LR initiation in WT, ore1-2 mutant and ore1-2 expressing the cell death inducing $\mathrm{mBAX}$ protein under the transcriptional control of the BFN1 promoter.

Each line was compared with the corresponding wild type by Pearson's chi-square test, to reveal potential differences in the distribution of LRP stages dependent on genotype (n.s.: not significant, *: $\left.p<0.05,{ }^{* *}: p<0.01, * * *: p<0.001\right)$. In (b), $20<n<31$, while in (a), $n=30$ observed seedlings.

File name: Supplementary Movie 1

Description: Light sheet microscopy time-lapse imaging of the endodermal plasma membrane marker proCASP1::CIT:SYP122 and the cell death marker proBFN1::nucGFP around a developing LRP.

File name: Supplementary Movie 2

Description: Light sheet microscopy time-lapse imaging of the endodermal plasma membrane marker proCASP1::CIT:SYP122 and the cell death marker proBFN1::nucGFP around a developing LRP (Fig. 2i). The central, elongated nuclear signal comes from the vasculature while the two nuclear signals from the right come from two overlying endodermal cells.

File name: Supplementary Movie 3

Description: Depth-wise movie of light sheet microscopy imaging of the endodermal plasma membrane marker proCASP1::CIT:SYP122 and the cell death marker proBFN1::nucGFP around a developing LRP (Fig. 2i) at the time of disintegration of a marked nucleus. The presence of a LRP can be deduced from the bent shape of the overlying endodermal cells.

File name: Supplementary Movie 4

Description: Time-lapse confocal microscopy 3D projection of the BFN1 promoter driven tonoplast marker (proBFN1::ToIM) line in Arabidopsis roots. The signal appearing shortly on the left-hand side comes from the vasculature while the signal from the right comes from an overlying endodermal cell.

File name: Supplementary Movie 5

Description: Time-lapse confocal microscopy 3D projection of the BFN1 promoter driven tonoplast marker (proBFN1::ToIM) line in Arabidopsis roots. The signal appearing shortly on the left-hand side comes from the vasculature while the signal to the right comes from an overlying endodermal cell. 
bioRxiv preprint doi: https://doi org/10.1101/268433; this version posted February 20, 2018. The copyright holder for this preprint (which was not certified by peer review) is the author/funder, who has granted bioRxiv a license to display the preprint in perpetuity. It is made available under aCC-BY-NC-ND 4.0 International license.

Table S1: List of $\mathbf{5 0}$ genes most correlated with BFN1 expression in the LR transcriptome. Sorted after decreasing Pearson correlation with BFN1 expression. Selected "cell death indicator genes" are highlighted in grey.

\begin{tabular}{|c|c|}
\hline AT1G11190 & BFN1 (BIFUNCTIONAL NUCLEASE I); single-stranded DNA specific endodeoxyribonuclease \\
\hline AT5G04200 & MC9 (metacaspase 9); cysteine-type peptidase \\
\hline AT2G44770 & ELMO/CED-12 family protein \\
\hline AT4G18425 & DMP4 (paralog of DMP2) \\
\hline AT1G26820 & RNS3 (RIBONUCLEASE 3); RNA binding / endoribonuclease/ ribonuclease T2 \\
\hline AT4G17220 & ATMAP70-5 (microtubule-associated proteins 70-5); microtubule binding \\
\hline AT4G34320 & unknown protein \\
\hline AT1G55180 & PLDEPSILON (PHOSPHOLIPASE D ALPHA 4); phospholipase D \\
\hline AT4G24430 & Rhamnogalacturonate lyase family protein \\
\hline AT3G20850 & proline-rich family protein \\
\hline AT2G14095 & EXI1 (EXITUS1) \\
\hline AT2G37670 & WD-40 repeat family protein \\
\hline AT4G39540 & ATSK2 (shikimate kinase 2) \\
\hline AT1G11160 & Transducin/WD40 repeat-like superfamily protein \\
\hline AT5G16600 & MYB43 (myb domain protein 43); DNA binding / transcription factor \\
\hline AT5G54850 & unknown protein \\
\hline AT3G21700 & Ras-related small GTP-binding family protein \\
\hline AT1G63600 & Receptor-like protein kinase-related family protein \\
\hline AT2G15320 & Leucine-rich repeat (LRR) family protein \\
\hline AT1G01780 & LIM domain-containing protein \\
\hline AT1G69580 & Homeodomain-like superfamily protein \\
\hline AT3G03000 & calmodulin, putative \\
\hline AT3G08930 & LMBR1-like membrane protein \\
\hline AT1G09540 & MYB61 (MYB DOMAIN PROTEIN 61); DNA binding / transcription factor \\
\hline AT2G47830 & cation efflux family protein / metal tolerance protein, putative (MTPc1) \\
\hline AT3G23870 & unknown protein \\
\hline AT4G28290 & unknown protein \\
\hline AT5G58940 & CRCK1 (CALMODULIN-BINDING RECEPTOR-LIKE CYTOPLASMIC KINASE 1); ATP binding / serine/threonine kinase \\
\hline AT1G34540 & CYP94D1; electron carrier/ heme binding / iron ion binding / monooxygenase/ oxygen binding \\
\hline AT3G51770 & ETO1 (ETHYLENE OVERPRODUCER 1); protein binding, bridging \\
\hline AT3G25805 & unknown protein \\
\hline AT2G37810 & CHP-rich zinc finger protein, putative \\
\hline AT5G13990 & ATEXO70C2 (exocyst subunit EXO70 family protein C2); protein binding \\
\hline AT1G60890 & phosphatidylinositol-4-phosphate 5-kinase family protein \\
\hline AT1G61950 & CPK19; ATP binding / calcium ion binding / calmodulin-dependent protein kinase / serine/threonine kinase \\
\hline AT5G15600 & SP1L4 (SPIRAL1-LIKE4) \\
\hline AT1G05310 & pectinesterase family protein \\
\hline AT4G10370 & DC1 domain-containing protein \\
\hline AT1G54060 & ASIL1 (ARABIDOPSIS 6B-INTERACTING PROTEIN 1-LIKE 1); sequence-specific DNA binding / transcription factor \\
\hline AT3G14640 & CYP72A10; electron carrier/ heme binding / iron ion binding / monooxygenase/ oxygen binding \\
\hline AT4G01110 & unknown protein \\
\hline AT4G09890 & unknown protein \\
\hline AT1G01140 & CIPK9 (CBL-INTERACTING PROTEIN KINASE 9); ATP binding / kinase/ protein kinase/ protein serine/threonine kinase \\
\hline AT4G17170 & RABB1C (ARABIDOPSIS RAB GTPASE HOMOLOG B1C); GTP binding / GTPase \\
\hline AT5G03640 & protein kinase family protein \\
\hline AT2G11150 & transposable element gene \\
\hline AT4G18430 & AtRABA1e (Arabidopsis Rab GTPase homolog A1e); GTP binding \\
\hline AT2G20880 & AP2 domain-containing transcription factor, putative \\
\hline AT5G44700 & GSO2 (GASSHO 2); ATP binding / protein binding / protein kinase/ protein serine/threonine kinase/ protein tyrosine kinase \\
\hline AT5G47250 & disease resistance protein (CC-NBS-LRR class), putative \\
\hline AT4G35190 & LOG5 (LONELY GUY 5); putative lysine decarboxylase family protein \\
\hline
\end{tabular}




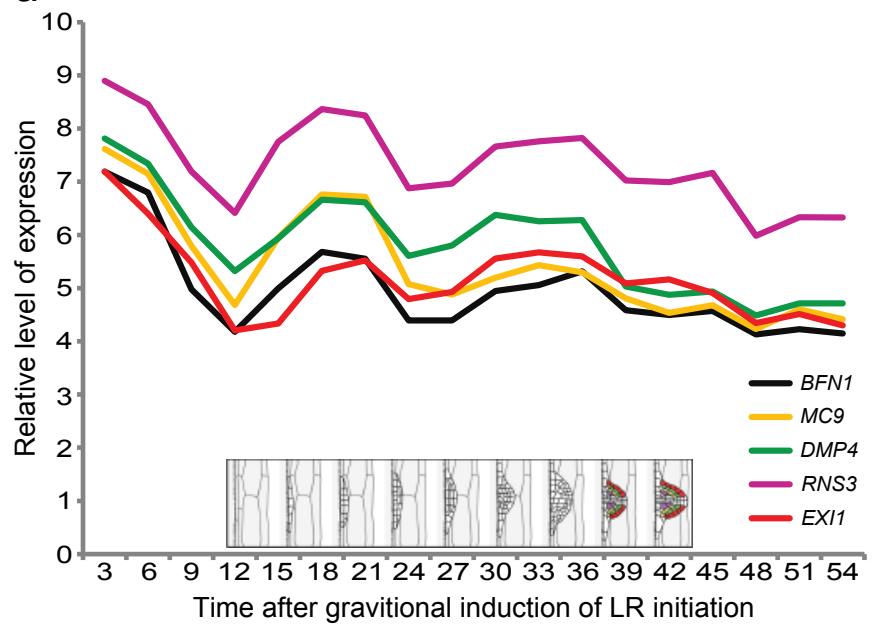

b
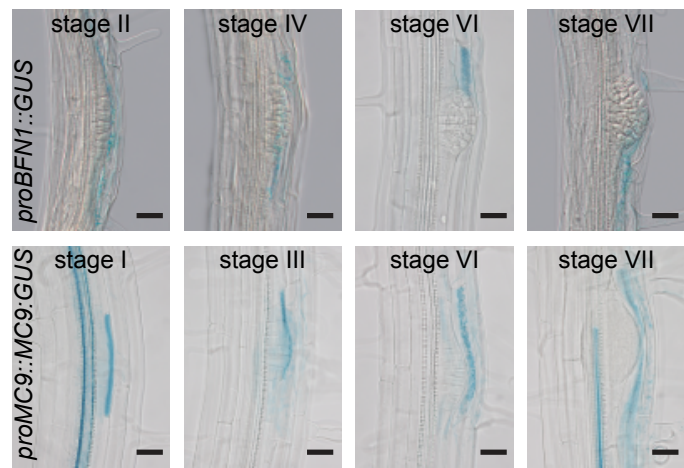

stage VII
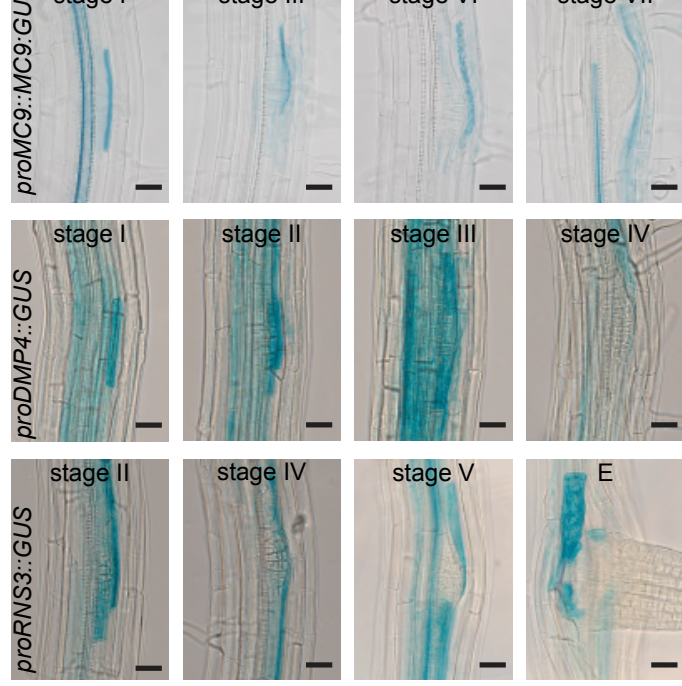

Figure 1: Transcriptional activation of cell death indicator genes in LRP-overlying cells

(a) Expression profile of BFN1 and four highly correlated cell death indicator genes in the lateral root (LR) emergence time course transcriptomics dataset from ref 34 . (b) Promoter activity profile of the cell death indicator genes BFN1, MC9, DMP4 and RNS3 in the tissues overlying naturally initiated lateral root primordia (LRP) at the indicated stages. Bars $=25 \mu \mathrm{m}$. Note that in addition to signal in the overlying cells there is also often signal in the protoxylem vessel. 

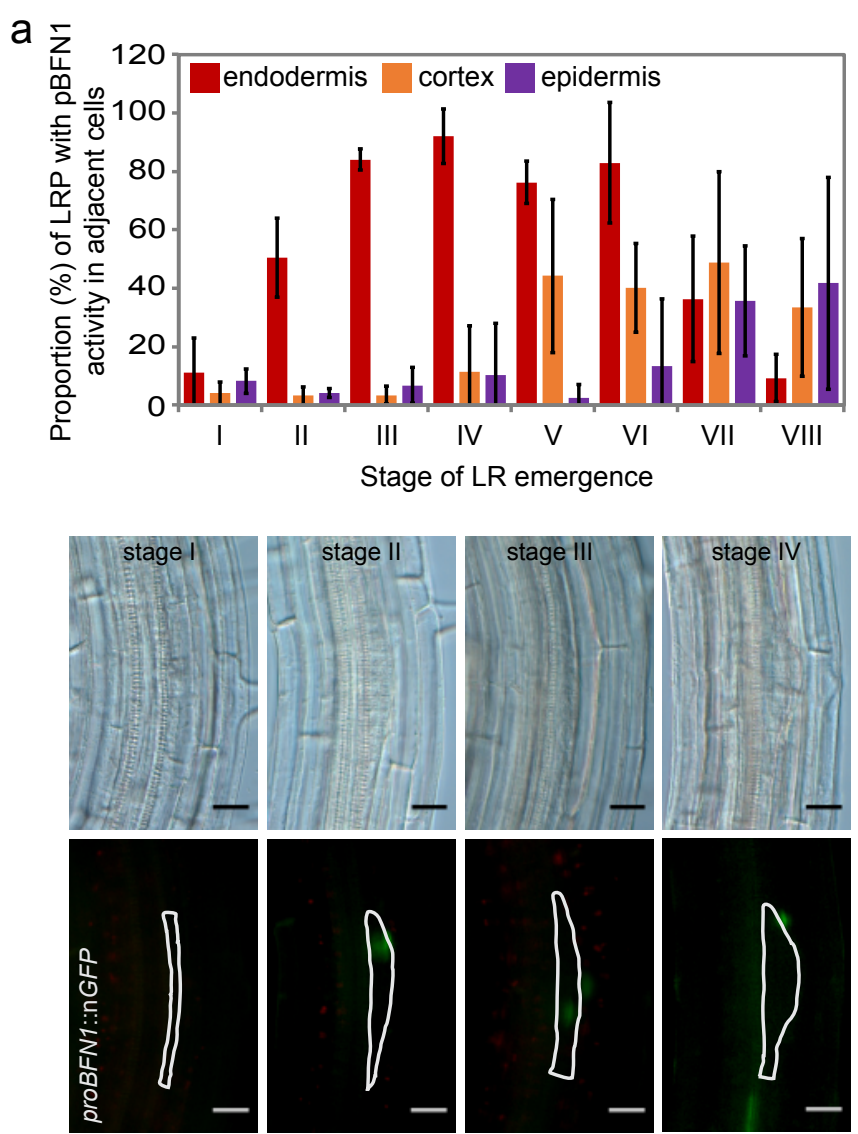

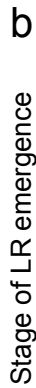

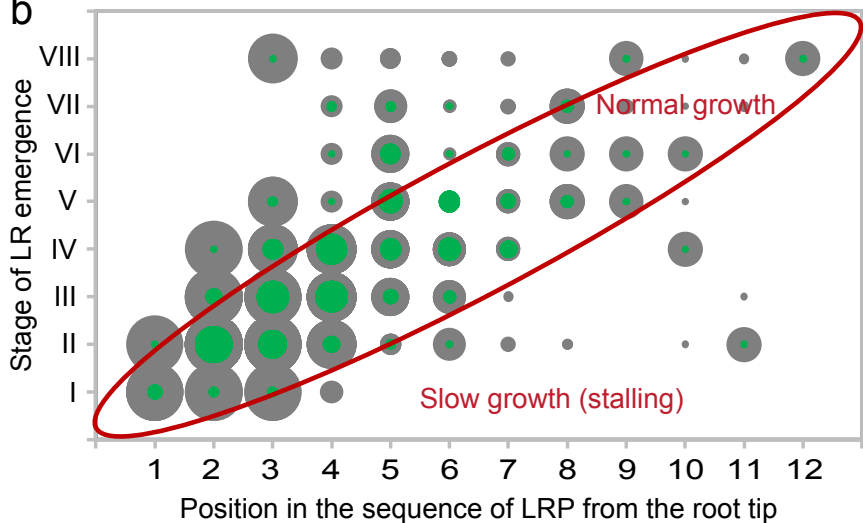

Figure 2: Expression patterns of cell death indicator genes in LRP-overlying cells in relation to LRP progression

(a) Proportion of LR primordia (LRP) displaying nuclear GFP signal in at least one LRP adjacent endodermal cell (red), cortical cell (orange), or epidermal cell (purple), for each stage of LRP development in the proBFN1::nucGFP seedling roots. Values represent averages of three replicate experiments, each including 20 seedlings and over 100 primordia. Error bars indicate SD. The micrographs in the lower panels illustrate how the data was acquired by differential interference contrast microscopy (upper row) for analysis of the LRP stage and by fluorescence microscopy (lower row) for GFP signal count in the marker line proBFN1::nucGFP. The LRP shape is delineated by a white line in the fluorescence micrographs. Bars $=25 \mu \mathrm{m}$.

(b) Visualization of LRP stage distribution in terms of LRP sequence from the root tip of 60 5-6 days old Arabidopsis seedlings. The size of each dot is proportional to the number of observed LRP at each stage and position in total (grey) or with at least one proBFN1::nucGFP-positive overlying cell (green). $\mathrm{E}=$ emerged. 

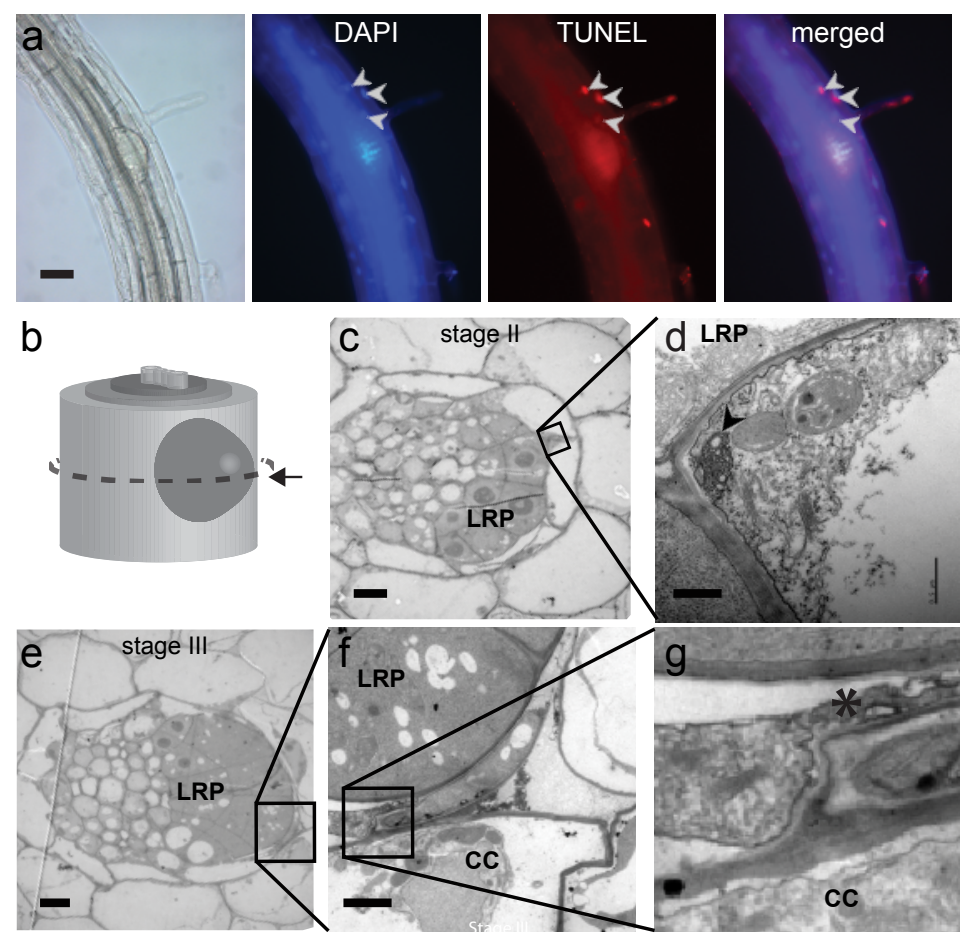
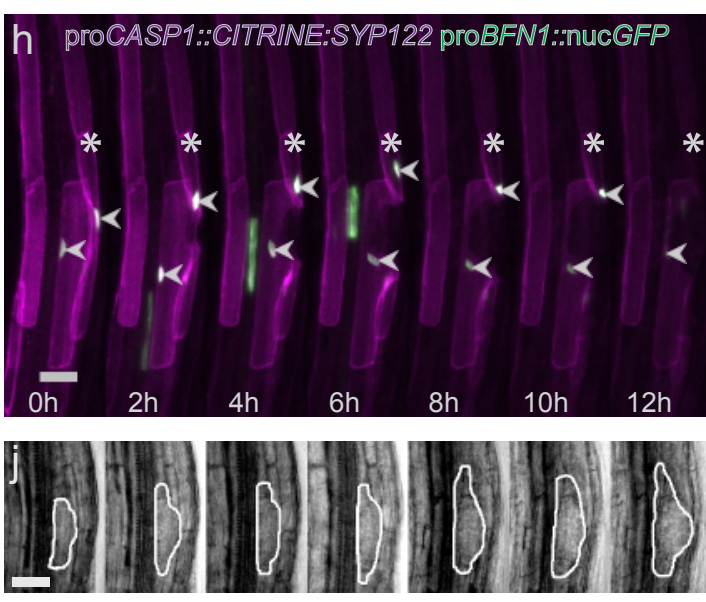

$\mathrm{k}$

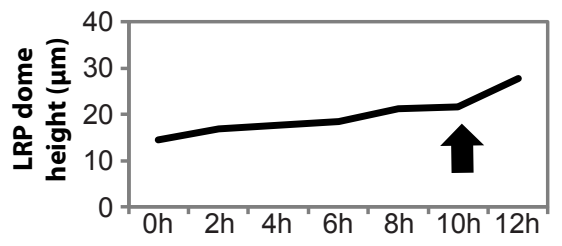

(1)

\section{Figure 3: Detection of cell death in LRP-overlying cells}

(a) Fluorescence micrography detection of cell death-associated nuclear degradation with TUNEL (red) and ubiquitous nuclear staining with DAPI (blue). Arrowheads indicate TUNEL-positive nuclei in LRP-overlying cells. Bar $=50 \mu \mathrm{m}$.

(b-g) Transmission electron micrography of cross sections through a lateral root primordium (LRP) and the surrounding tissues. The position of the cross section within the root is shown in (b). Stage II (c,d) and stage III (e-g) LRPs are shown. (d) is a magnification from (c). ( $g$ ) is a magnification of $(f)$ which itself is a magnification of (e). The arrowhead indicates apparent loss of plasma membrane integrity while the asterisk indicates leakage of intracellular material. LRP, lateral root primordium; CC, cortical cell. Bar = $5 \mu \mathrm{m}$ (c,e), 2 $\mu \mathrm{m}(\mathrm{f})$ and $0.5 \mu \mathrm{m}(\mathrm{d})$.

(h) Time-lapse confocal microscopy 3D projection of the endodermal plasma membrane marker proCASP1::CIT:SYP122 (purple) and the nuclear cell death reporter proBFN1::nucGFP (green) around a developing LRP. The asterisks mark the endodermal cell which ultimately dies (between 10h and 12h) while the arrowheads point at the endodermal nuclei displaying GFP signal. The elongated area with GFP signal seen in the stele from $2 \mathrm{~h}$ to $6 \mathrm{~h}$ is the nucleus of a xylem tracheary element undergoing developmental cell death and autolysis. Bar $=25 \mu \mathrm{m}$.

(i) Kymographs of 3D projection from light sheet microscopy time-lapse imaging of the endodermal plasma membrane marker proCASP1::CIT:SYP122 and the nuclear-localized cell death indicator gene transcriptional reporter proBFN1::nucGFP around a developing LRP. The presence of a LRP can be deduced from the bent shape of the overlying endodermal cells. Asterisks indicate time points when an endodermal nucleus is seen to disintegrate or to disappear. Arrowheads point at disintegrating nuclei. Bars $=20 \mu m$.

(j) Transmission light images corresponding to images in (h). The LRP are highlighted by white lines. Bars $=25 \mu \mathrm{m}$.

(k) Dome height (in $\mu \mathrm{m}$ ) of the LRP from $(\mathrm{h}, \mathrm{j})$ over the $12 \mathrm{~h}$ monitoring period of LRE. The black arrow indicates acceleration of LRP growth along its length axis concomitant with the death of an overlying cell. 


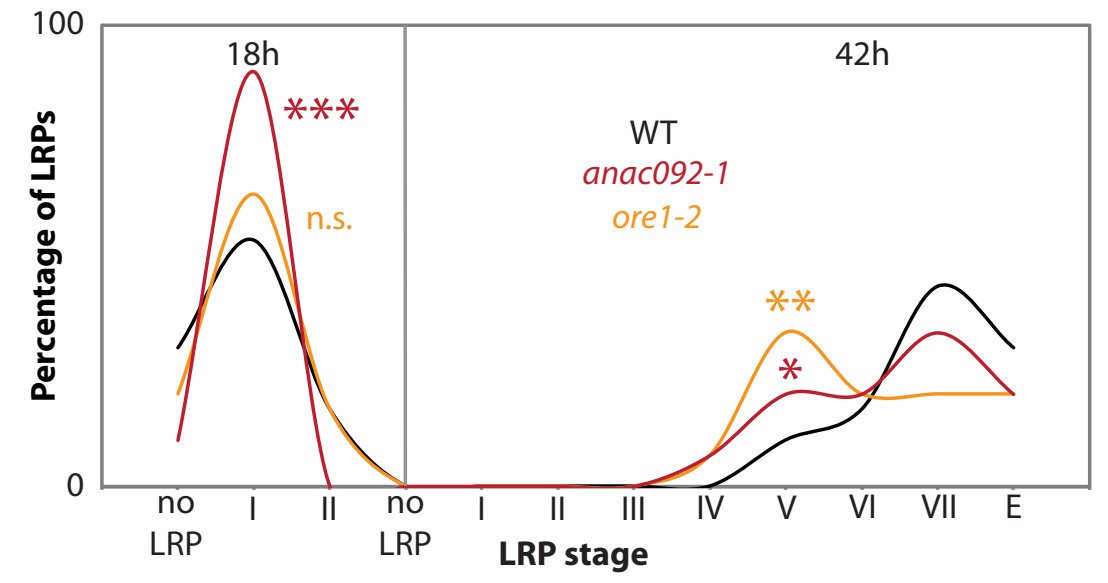

b

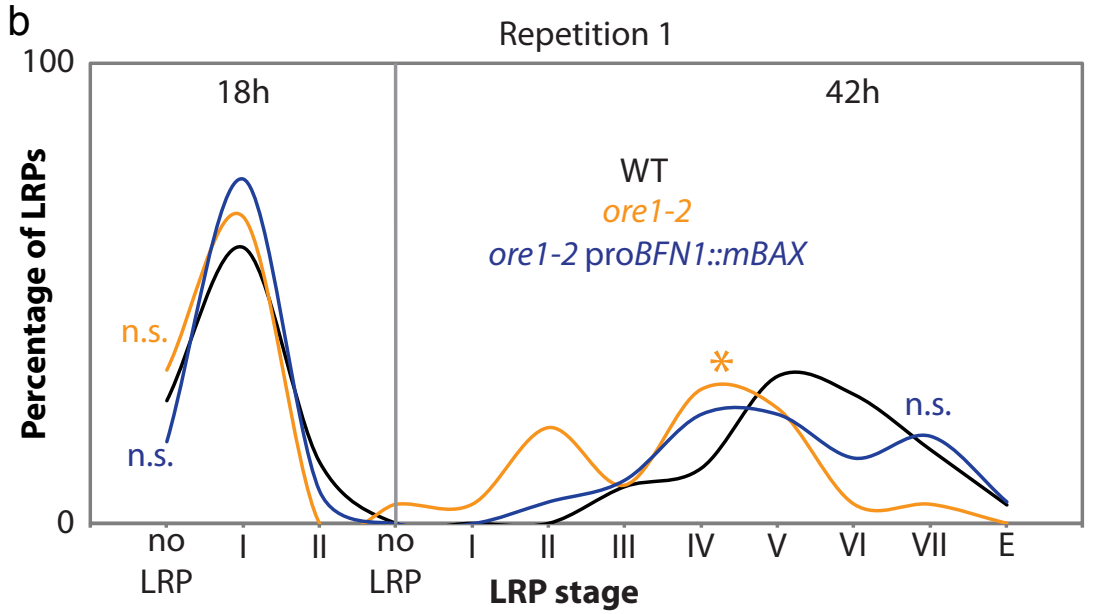

Figure 4: LRE is delayed by loss of the positive cell death regulator ORE1 and rescued by inducing cell death in overlying cells

(a) Distribution of observed lateral root primoridum (LRP) stages $18 \mathrm{~h}$ and $42 \mathrm{~h}$ after gravitational induction of lateral root (LR) initiation in wild-type (WT) and two mutant alleles for ORE1.

(b) Distribution of observed LRP stages $18 \mathrm{~h}$ and $42 \mathrm{~h}$ after gravitational induction of LR initiation in WT, ore 1-2 mutant and ore 1-2 expressing the cell death inducing $\mathrm{mBAX}$ protein under the transcriptional control of the BFN1 promoter.

Each line was compared with the corresponding wild-type by Pearson's chi-square test, to reveal potential differences in the distribution of LRP stages dependent on genotype (n.s.: not significant, *: $p<0.05,{ }^{* *}: p<0.01$, ***: $p<0,001)$. In (b), $20<n<31$, while in (a), $n=30$ observed seedlings. 

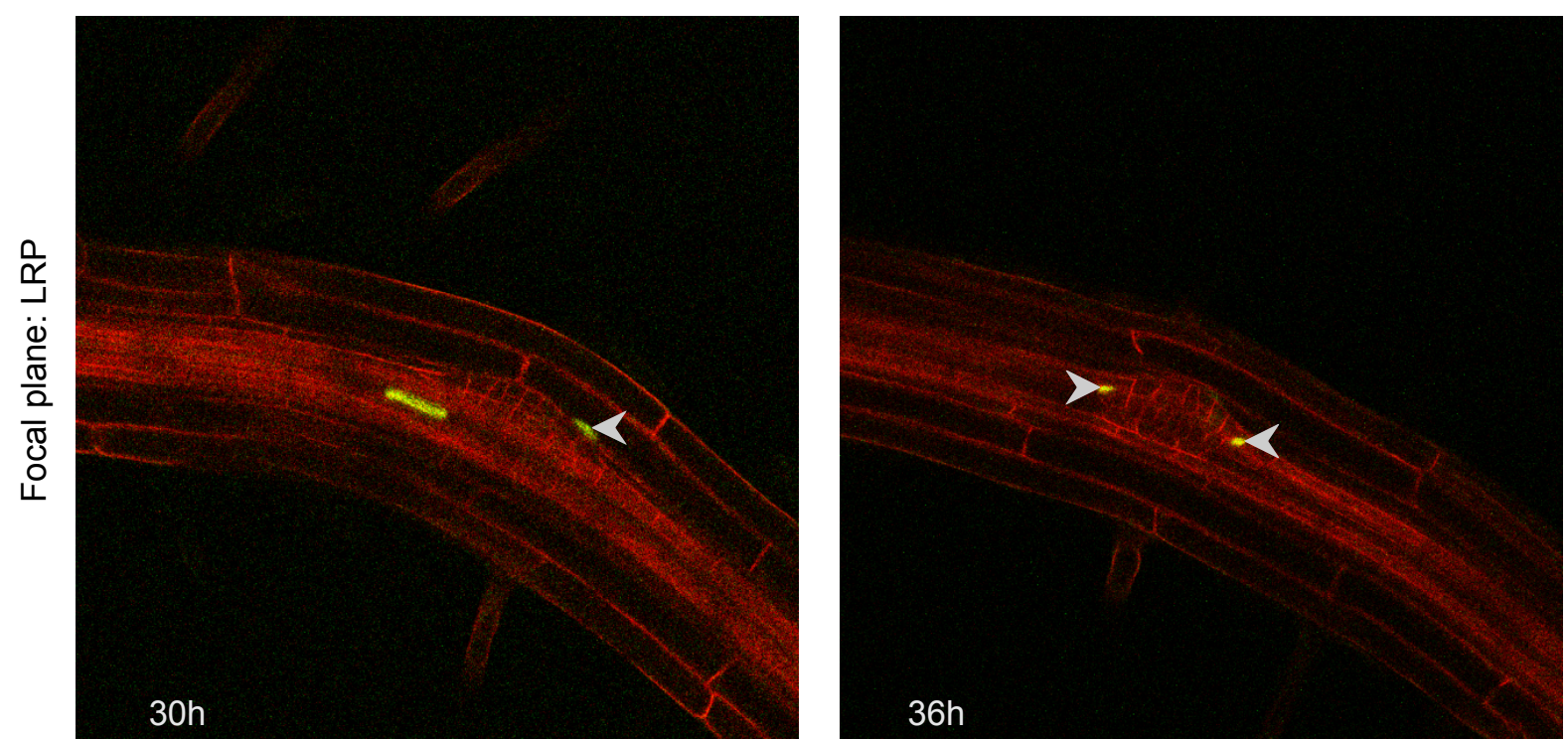

\section{Figure S1: Vizualization of proBFN1 activation in cells overlying early-stage LRP}

proBFN1::nucGFP expression at two time points during lateral root emergence (LRE) of a gravitationally induced lateral root (LR) in proUBQ10::WAVE131:YFP (ubiquitous plasma-membrane marker) background. Arrowheads indicate GFP-positive nuclei in overlying cells, while the elongated fluorescent nucleus in the stele belongs to a xylem tracheary element, a cell type known to undergo cell death. 
b
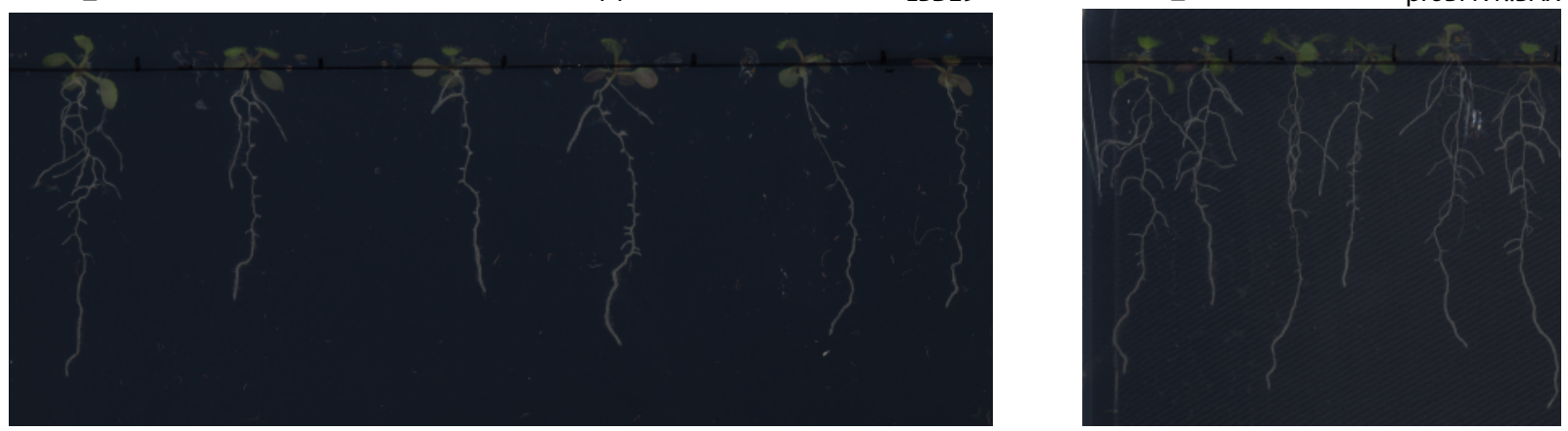

ore 1-2

C
Col_0
ore 1-2
anac092-1

anac092-1

ore1-2
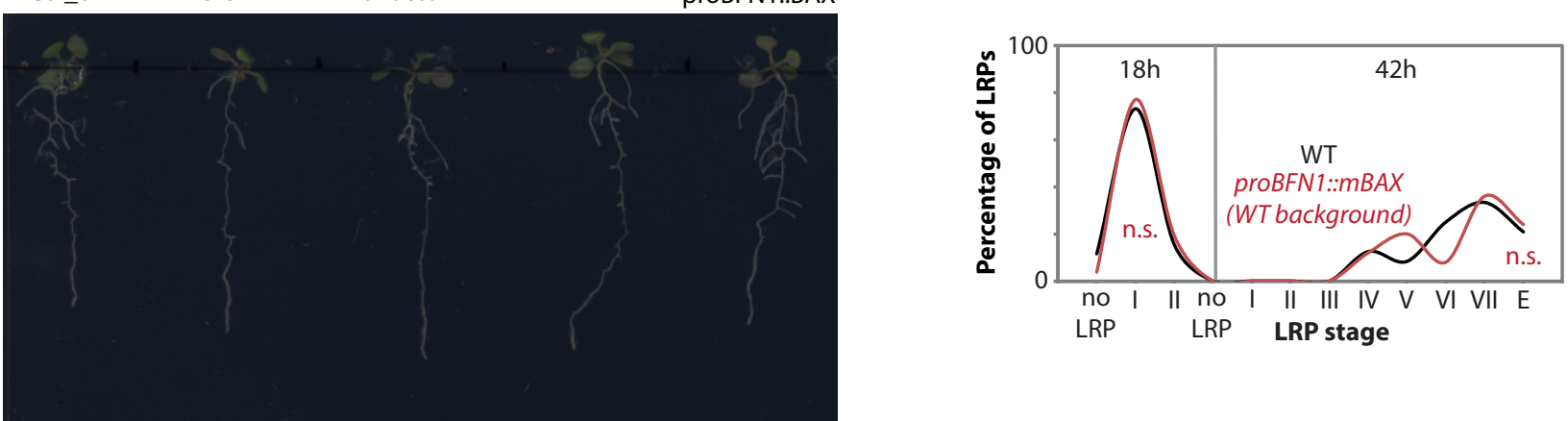

d
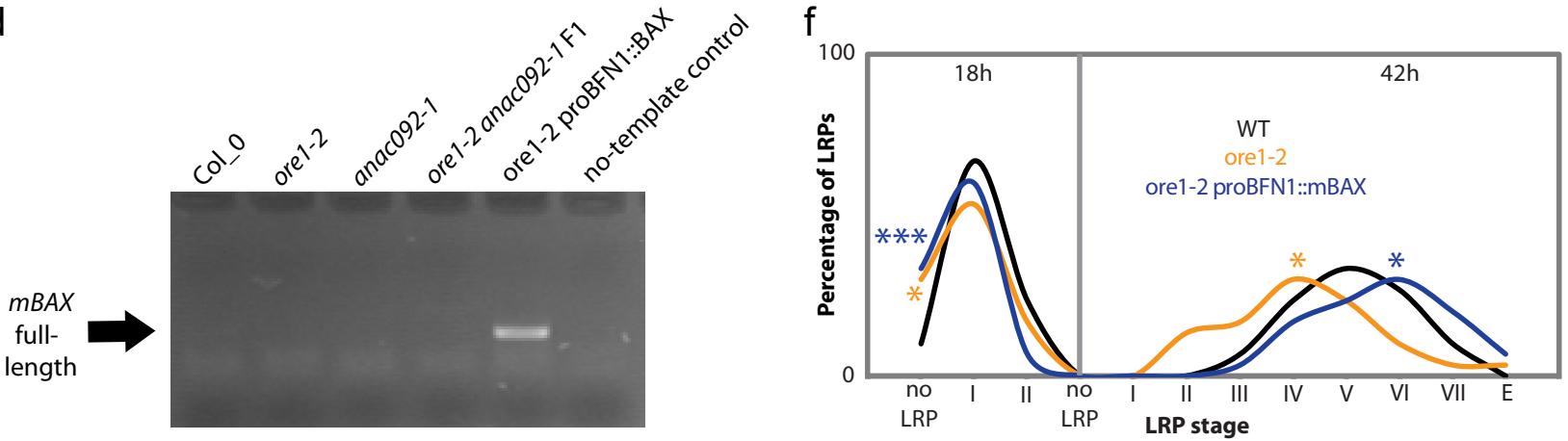

Figure S4: Characterization and rescue of the lateral root emergence phenotype in mutants for the positive cell death regulator ORE1

(a-c) Images of seedlings illustrate the differences in the numbers of emerged lateral roots (LRs) between the indicated genotypes grown next to one-another (i.e. in the same conditions).

(d) The gel image displays an agarose gel electrophoresis with products from PCRs with cDNA from the indicated genotypes and designed to amplify the mamalian $m B A X$ transcript, which has been introduced in the ore 1-2 mutant background.

(e) The chart shows the results of a staging assay comparing LR emergence between wild-type plants (WT) and plants expressing the cell death inducing mammalian protein mBAX under the transcriptional control of the BFN1 promoter (in the WT background). n.s. indicates that there is no statistically significant difference.

(f) Distribution of observed LRP stages $18 \mathrm{~h}$ and $42 \mathrm{~h}$ after gravitational induction of LR initiation in wild-type, ore 1-2 mutant and ore 1-2 expressing the cell death inducing $\mathrm{mBAX}$ protein under the transcriptional control of the BFN1 promoter. Each line was compared with the corresponding wild-type by Pearson's chi-square test, to reveal potential differences in the distribution of LRP stages dependent on genotype (n.s.: not significant, ${ }^{*}: p<0.05,{ }^{* *}: p<0.01,{ }^{* *}: p<0,001$ ). $n=30$ observed seedlings per genotype and per time-point. 
Col_0

ore1-2

ore1-2

pBFN1::mBAX
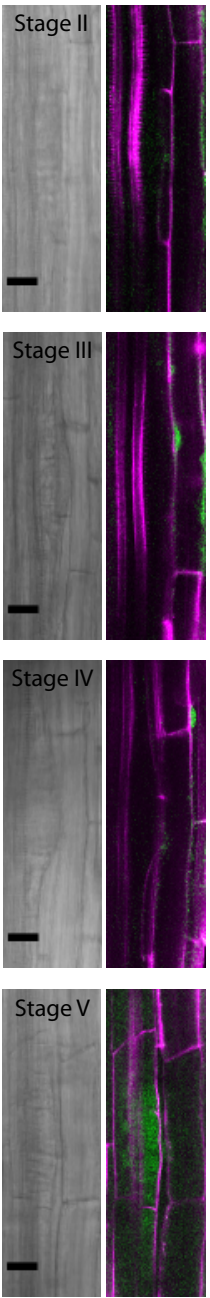
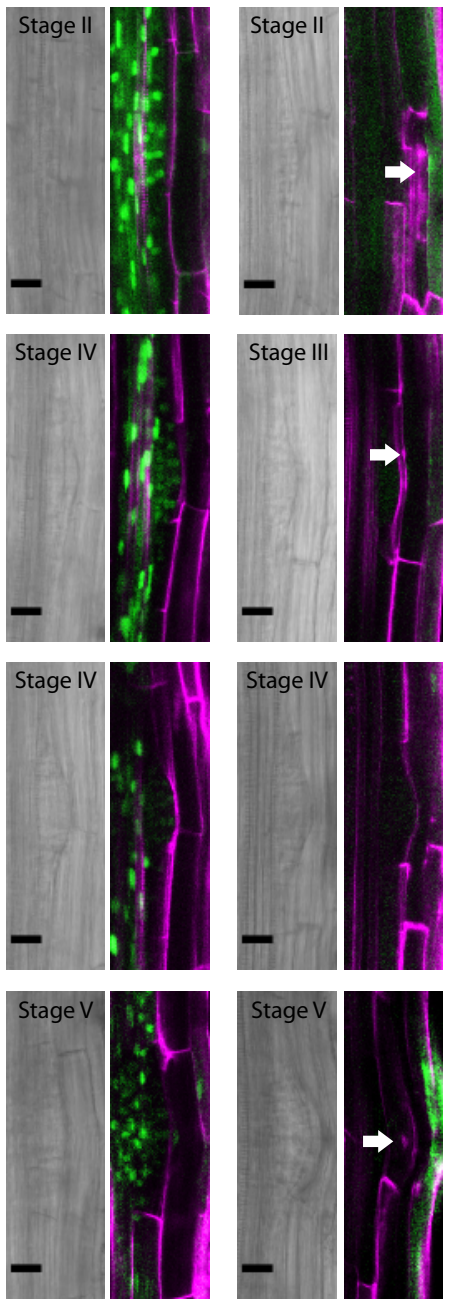

Figure S5: Evidence for mBAX-induced cell death in LRP overlying cells

Transmission light (left) and fuorescence (right) micrographs from confocal laser scanning microscopy imaging of LRPs and of the overlying cells in the main roots of 6 days old Arabidopsis seedlings. The seedlings were stained with propidium iodide (magenta) and fluorescein diacetate (FDA; viability staining; green). White arrows point at cells displaying signs of cell death and autolysis, as revealed by complete lack of FDA signal as well as by propidium iodide staining of the nucleus or of collapsed protoplast remains. 